\title{
TEACHING PROBLEM-SOLVING STRATEGIES IN MATHEMATICS
}

\author{
Eva Fülöp \\ University of Gothenburg • eva.fulop@gu.se
}

\begin{abstract}
This study uses the methodology of design-based research in search of ways to teach problem-solving strategies in mathematics in an upper secondary school. Educational activities are designed and tested in a class for four weeks. The design of the activities is governed by three design principles, which are based on variation theory. This study aims to contribute to an understanding of how the teaching of problem-solving strategies and strategy thinking in mathematics can be organized in a regular classroom setting and how this affects students' learning in mathematics. We start by discussing the nature of the concept strategy in relation to the concepts of method and algorithm. Using pre- and post-tests, we compare the development of the students' conceptual and procedural abilities with a control group. In addition, we use the post-test to investigate the students' use of problem-solving strategies. The results suggest that these designed activities improve students' ability to use problem-solving strategies. Moreover, significant differences were found in conceptual and procedural abilities in mathematics, the experimental group improving more than the control groups.
\end{abstract}

\section{Introduction}

Problem-solving and strategy thinking play a crucial role in both everyday and professional life, in a world that is becoming more and more turbulent and characterized by rapid technological innovations, shifting political alliances and emerging economies (NCSM, 1977; Mason, 1982; Sloan, 2006; Goldman, 2012). Hence, for the past 40 years, problem solving has emerged as one of the major concerns at all levels of school mathematics. Can knowledge about problem-solving strategies improve a person's problem-solving skills? This question will not be answered in this short study. We will rather assume that knowledge about problem-solving strategies is an important part of mathematical knowledge. From a Swedish perspective, there is also a demand to include strategies in the teaching of mathematics, as the Swedish curriculum states that teaching of mathematics should aim at developing an understanding of different strategies for solving mathematical problems (Swedish National Agency for Education, 2011).

But what is a problem-solving strategy? Furthermore, what is most essential when learning about problem-solving strategies and what learning approaches could be used to become successful at using strategies? The study presented in this paper has contributed to extending knowledge about developing, enacting, and sustaining innovative learning environments that promote knowledge about problem-solving strategies. The aims of the study are to examine ways of teaching problem-solving strategies in mathematics in upper secondary school, through specially designed activities, and how this affects students' problem-solving, conceptual and procedural abilities. This study was conducted using a 
design-based research (DBR) methodology and used teaching interventions intended to support 16 and17 year old students in identifying problem-solving strategies and experiencing strategy thinking. The teaching intervention was designed to fit into the regular teaching, without altering the mathematical content but adding learning of strategy thinking. This text summarizes the results after the first four weeks of a year-long experiment.

This paper begins by clarifying the nature of the concept strategy in professional life and in school mathematics. This is done by presenting a historical overview of perspectives on the strategy concept. We discuss the nature of the concept in relation to the concepts of method and algorithm. Then we describe our chosen design principles and methods, and also the results from our study. Finally we put forward some recommendations for developing the use of strategies in mathematical problem solving in classroom situations.

\section{Background}

\subsection{What is a strategy?}

There is remarkably little agreement on what strategy in mathematical problem solving is. Investigating problem solving more broadly, one finds that one can distinguish a thinking and a doing aspect, regardless of whether we speak about military, management or game theory (Vego, 2012; Grant, 2008; Zagare, 1984). Essentially, strategy is the thinking aspect of organizing a war, of winning a game, or of keeping a business organization moving in a deliberately chosen direction by laying out goals and ideas. In contrast to strategy, the tactics in military theory, the choices in game theory, the detailed plan in management theory are in the intersection between the thinking and the doing aspect, producing a plan for a specific action. But in order to actually achieve these goals, problem solving must also be about how people will act at the operational level to win the battle, which moves they make in the game or how carefully they follow the project plan in an organization.

In mathematical problem-solving situations, Schoenfeld (1983) describes two different types of decision making, the "what to do" and the "how to" do decisions. The first of these types, the strategic decisions, includes selecting goals and deciding to pursue courses of action. The second one, the "tactics", includes decisions about how to implement the decisions of the first type, but at the end the students need to apply the procedures relevant for the solution of the problem. So to become a good problem solver in mathematics requires developing a personal and idiosyncratic collection of problem-solving strategies (Schoenfeld, 1985). As a consequence, one of the most important responsibilities of educators should be to facilitate the development of proper problem-solving skills, which include knowledge about strategies (Posamentier \& Krulik, 1998).

Pólya (1945,1962) and Posamentier \& Krulik (1998) present ad hoc examples of problem-solving strategies but do not give any general definition or general characteristics of strategies. In their book, Posamentier and Krulik (1998) present ten problem-solving 
strategies that seem to be prevalent in problem-solving situations in mathematics. They argue for the importance of familiarizing both teachers and students with these strategies, in order to make them part of the students' thinking processes. To actually make use of problem-solving strategies there is a need for practices that encourage a culture of strategy thinking, and also an ability to recognition that a change is needed in the problem-solving situation when you are stuck (Mason, 1982; Goldman, 2012).

The strategies mentioned in the book are Visualization, Organizing Data, Finding a Pattern, Solving a Simpler Analogous Problem, Working Backwards, Adopting a different point of view, Intelligent Guessing and Testing, Logical reasoning, and Considering extreme cases. But the list that Posamentier and Krulik (1998) present in their book is not a complete list of problem-solving strategies. Other books on the subject also include other strategies. In some cases the authors refer to these strategies as methods, but the meaning behind them is the same. One of the critical aspects of these strategies is their general character, their independence of any particular topic or subject matter.

\subsection{Learning strategy thinking}

By investigating the learning of strategy thinking, we can see that strategy thinking is an ability that can be developed over time and that at least three factors are important in this development (Sloan, 2006; Casey and Goldman, 2010; Mintzberg, 1994a; Ansoff, 1991; Armstrong, 1982; Grinyer, Al-Bazzaz \& Yasai-Ardekani, 1986; Goldman, 2012; Gravemeijer \& Doorman, 1999; Stigler \& Hiebert, 1999). First there is the benefit of dialogue. Sloan (2006) sees strategy thinking as a mental process and highlights the importance of dialogue for the creative and cognitive learning process. The same ideas can be found in cooperative learning in Japanese lessons (Stigler and Hiebert 1999). Cooperative learning makes the students spend more time on the task compared with when they work alone (ibid.). In this way they get the opportunity to have a creative discussion with others.

Actual opportunities for students to learn also depend on the kind of interaction that takes place during problem solving, both between the teacher and the students and among the students. Considerable theoretical and empirical evidence suggests a strong connection between classroom interaction and student learning. The theoretical support comes from both constructivist and sociocultural perspectives on learning (e.g., Cobb, 1994; Hatano, 1988; Hiebert et al., 1997).

Second there is the importance of experiential learning. Goldman (2012) sees strategy thinking as an activity, and suggests a dynamic, interactive, and iterative process of experiential learning. According to variation theory, there is a difference between "being told" something and "experiencing a variation of different features" of an object of learning. (Marton \& Tsui, 2004). The learning environment of teaching through problem solving provides a natural setting for students to present various solutions to their group or class and learn mathematics through social interactions, meaning negotiation, and reaching shared understanding. Such activities help students to clarify their ideas and acquire 
different perspectives on the concept or idea that they are studying. Empirically, teaching mathematics through problem solving helps students go beyond acquiring isolated ideas, and to move toward developing an increasingly connected and complex system of knowledge (e.g., Cai, 2003; Carpenter, Franke, Jacobs, Fennema, \& Empson, 1998; Hiebert \& Wearne, 1993). The power of problem solving is that obtaining a successful solution requires students to refine, combine, and modify knowledge they have already learned.

Third we consider the importance of an appropriate task that can lead to experiential mathematical learning or creative dialogues. It is important that the task is or becomes a genuine problem for the students, either because the students cannot directly apply methods and algorithms to solve it or because it is a task with multiple solutions where the students are asked to come up with different ways of solving the problem. According to Gravemeijer and Doorman (1999), "Well-chosen context problems offer opportunities for the students to develop informal, highly context-specific solution strategies." Getting stuck for a while is very helpful because it provides an opportunity to experience the creative side of mathematical thinking (Mason et al., 1982).

\section{Research aim and question}

The aim of this study is to discern critical aspects of the concept of strategy and to explore and understand the educational possibilities of teaching problem solving strategies. The question is as follows:

What is the effect on the students `ability to use problem-solving strategies and on their conceptual and procedural knowledge when problem-solving strategies are included in the teaching of mathematics in the regular mathematics classroom?

\section{Methodological considerations}

\subsection{Design, research and practice}

Design experiments manifest both scientific and educational values through the active involvement of researchers in learning and teaching procedures. There are different terms for design research in the literature: design-based research (DBSC, 2003; Anderson \& Shattuck, 2011; Anderson, 2005), design experiments (Brown, 1992; Collins, 1992, 1999; Cobbs et al., 2003; Zhang et al., 2009), design research (Edelson, 2002), action research (Servan et al., 2009), development research (van den Akker, 1999), developmental research (Richey, Klein \& Nelson, 2003), formative research (Reigeluth \& Frick, 1999),instructional design (Magidson, 2005). All design research methods are characterized by iterative design and formative research in real-world settings with regard to the following aspects: (1) collaboration between practitioners and researchers (2) implementation of theories for testing or developing and refining of theories (3) the possibility of contributing to the growth of educational reform (4) a focus on designing and exploring innovations.

This study was conducted using a design-based research methodology (Wang \& Hannafin, 2005; DBSC, 2003). A clear advantage of DBR is that it leads to the development 
of knowledge that can be used in practice by directly involving researchers in the improvement of education and also leads to contextually sensitive design principles and theories. For this reason, DBR has the potential to generate theories that both meet teachers' needs and support educational reforms, since it is suitable both for research and for design of learning environments. These design principles tell us how to design learning situations that help students learn specific skills and concepts, in our case problem-solving strategies.

\subsection{Design principles}

It is very difficult to predict how students will respond to innovative instruction, so design principles, cycles of testing and revision are critical in design-based research. We have defined three design principles for the planning and implementation of teaching problemsolving strategies. In this study, we have chosen to use variation theory as the theoretical base for the design principles, as variation theory has been proved helpful when designing learning environments. (Marton and Booth, 1997; Häggström, 2008; Runesson, 2008; Wernberg, 2009; Kullberg, 2010)

"In using variation theory, the role of the teacher is to design learning experiences in such a way that helps students to discern the critical aspects of the object of learning with the use of variation. By consciously varying certain critical aspects, a space of variation is created that can bring the learner's focal awareness to bear upon the critical aspects, which makes it possible for the learner to experience the object of learning” (Pang \& Marton, 2005)

According to variation theory, the content itself is not the aim or the outcome of learning. Rather it is the capability to use the content that is the intended target or result for learning (Pang \& Marton, 2005).

We have formulated the following three design principles, which are firmly rooted in variation theory and are aimed at at designing activities for learning problem-solving strategies:

- Let the problem-solving strategy vary and keep the task invariant (DP 1)

- Let the task vary and keep the problem solving strategy invariant (DP 2)

- Let both the task and the strategy vary and allow students to evaluate the effectiveness of different strategies for different tasks (DP 3)

Table 1 How the content and the teaching arrangements were handled

\begin{tabular}{l|l|l|}
\multicolumn{1}{c|}{} & \multicolumn{1}{c|}{$\begin{array}{l}\text { Variation introduced by } \\
\text { students }\end{array}$} & $\begin{array}{l}\text { Variation introduced by the } \\
\text { teacher }\end{array}$ \\
\cline { 2 - 3 } $\begin{array}{l}\text { Problem-solving strategy varies } \\
\text { DP } 1\end{array}$ & Lesson 1 & Lesson 4 \\
\hline $\begin{array}{l}\text { Task varies } \\
\text { DP } 2\end{array}$ & Lesson 2 & Lesson 3 \\
\cline { 2 - 3 } & &
\end{tabular}


The design principles are used for governing the practical action of designing concrete learning situations. In this study we complete three cycles of designing, implementing and revision of lessons, incorporating the understanding and experience of the teacher about how the children interacted with the activities. Each cycle is delineated by different contexts, settings and content areas of mathematics.

\subsection{The teaching intervention}

An important aspect of our design is that we do not only implement the design of a single lesson but rather 24 lessons that stretch over four weeks, forming a coherent unit. The planning underwent multiple revisions during the experiment as I accumulated understanding and experience of how the students reacted to the tasks and the activities.

The design of each lesson involved goals for both what mathematical content within the curriculum should be learnt and also what aspects of problem-solving strategies should be uncovered. The design was then constructed according to the design principles mentioned above. Furthermore the importance of dialogue and experiential learning was also considered when formulating the tasks and organizing the lessons. The intention was to set up an interaction between the individual pupil's thinking and the other pupils' comments, and to formulate the task so that it becomes a problem to the students (Schoenfeld 1985). The different lessons vary with regard to which of the three design principles was used and also with regard to whether it was the students or the teachers that opened the dimension of variation.

\section{Lesson 1}

The aim of this lesson was to introduce problem-solving strategies and to show that several different strategies can be used to solve a given problem. The mathematical aim was to develop students' understanding of rational numbers. In this lesson I chose to use the first design principle: let the problem-solving strategy vary and keep the task invariant. In this first lesson, I chose a mathematically simple task that the students could easily solve. In order to make the task into a problem, I formulated the question so as to force the students to find several alternative ways to solve the task, rather than using their usual method.

Which one of the numbers is greater and why? Try to find different explanations for your answer.
a) $\frac{5}{2}, \frac{3}{2}$
b) $\frac{2}{3}, \frac{2}{5}$

At the beginning of the lesson I let the students discuss the task in small groups for 1015 minutes. After that every solution was presented and discussed with the whole class. However to save time and to make it less intimidating for the students (while still 
guaranteeing that the discussion was based on the students' thinking) the teacher wrote on the board while the students described their solution in words.

Almost all of the suggestions involved a reformulation of the task using diagrams or other symbolic representations that the students felt more comfortable with. In other words, the first step of almost every solution was to find an analogous problem by changing the representation of the problem. It is typical problem-solving behaviour to connect one's own knowledge with the problem at hand. (Lester and Kroll, 1993). This is actually a wellknown problem-solving strategy called Solving a simpler analogous problem. The students also used other strategies in their solutions, such as Adopting a different point of view. In this way different strategies could be introduced, while at the same time allowing the dimension of variation to be opened by the students.

One of the solutions involved rewriting the fractions as decimal numbers. These were then placed on the real number line. Looking at the position of the numbers on the number line then allowed the students to decide which number is bigger. This solution led the discussion to a third strategy, Visualization. Another group also used the strategy Visualization to decide which number was bigger, but this time they rewrote the fractions as amounts of water in beakers instead of using the number line. They reformulated the problem into an everyday problem. In the end, they counted the number of beakers to decide which number was bigger. The chosen strategy is the same but the method is different.

In a third solution, the students represented the fractions as percentages. In this way the students found it easier to decide whether the difference is positive or negative, which helped them to find an answer. In a fourth solution the students choose a third number to compare with. This solution didn't lead to a correct answer. They chose to compare with the number one, which was a good strategy, but a bad choice as both the original rational numbers are bigger then 1 .

As these four examples were discussed, this gave the students the opportunity to experience some of critical aspects of the concept of strategy. Two of these aspects are that not every chosen strategy leads to a solution and that a strategy is not uniquely connected to a problem. The following strategies were mentioned during the lesson: Visualization, Solving a simpler analogous problem, Adopting a different point of view.

\section{Method}

\subsection{Sample}

The students involved were from three classes, all from the same school. All participants were tenth grade students, 16 and 17 years of age. The experimental class consisted of of 29 students and the two classes constituting the control group consisted of 58 students altogether. This was a convenience sample consisting of students starting at the Natural Science Program at an upper secondary school this particular year. 
The Natural Science Program is the most mathematics-intense program in the Swedish upper secondary school, preparing the students for university studies. For the students, this was their first mathematics course in upper secondary school, called Mathematics 1c. The mathematical content of this part of the course covered understanding of numbers, arithmetic and algebra. More particularly, the topics included during this study were: properties of the whole numbers, different number bases, prime numbers and divisibility, real numbers written in different forms, including powers with real exponents, and finally generalization of the rules of arithmetic to algebraic expressions.

Three different types of data were collected.

- Pre-intervention activities: Pre-tests in written form with 78 students. The pretest was given in the first lecture to identify students' prior procedural and conceptual knowledge. The test had two parts.

The first part of the test consisted of mental calculation: addition, subtraction, multiplication and division of natural numbers. The maximum possible mark was 39 and this part of the test had a time limit of 6 minutes. The second part included 32 multiple-choice tasks about number sense with no time limit. This part contained two types of questions. The first type was about estimation, such as "Approximately how many days have you lived?" with answer alternatives: a) 5000; b) 50 ooo; c) 500 o0o and d) 5000 ooo and others were about comparison of numbers, such as "Which number is greater? $3 / 5$ or $5 / 3$ ".

- Post-intervention activities: Post-tests in written form. At the end of the first four weeks, all students took a 19-item achievement test on number sense. It focused on mental calculation, conceptual knowledge and problem-solving knowledge.

The post-test was designed to measure several abilities such as: the ability to use and describe the meaning of mathematical concepts and their interrelationships; the ability to manage procedures and solve tasks of a standard nature without tools; mathematical problem-solving; and reasoning. The mathematical context was understanding of numbers, arithmetic expressions and algebraic expressions. These four components were examined for several reasons. First, to check the procedural knowledge among the students after four weeks. Secondly, to see if there were effects from the special intervention on the students`ability to use problem-solving strategies in mathematical-problem solving situations. All student solutions of the pre-test and post-test were corrected by the same person in order to ensure the reliability of the data. The duration of the test was 120 minutes.

- Intervention activities: Field notes, photographs of the board 
The first two types of data were collected with the goal of analyzing effects of the lesson activities. The last type of data was collected for the analysis of the teaching intervention and for design improvements throughout the three cycles.

\subsection{Data analysis techniques}

\section{Content analysis}

The analysis of the post-test was done in two different ways. The first interpretation of the results is a systematic, objective description and quantification, using content analysis, of students' knowledge of problem-solving strategies. Content analysis is a qualitative method that provides a method for obtaining access to the words or visual communication messages of the text accounts offered by subjects (Cole, 1988). As a research method it is a systematic and objective means of describing and quantifying phenomena (Krippendorff, 1980). At the same time it offers an opportunity for researchers to learn and better understand the perspectives of the authors of the texts. Each test selected for analysis has been subjected to a content analysis by using coding categories derived directly from the text data. The analysis processes consisted of three phases: preparing, organizing and reporting. Observational notes were divided into meaningful units. Taking into account the context, these meaning units were condensed into a description closely following the text (the manifest content) and into an interpretation of the underlying meaning (the latent content). This model for content analysis of the post-test was employed to qualitatively analyze the students' use of problem-solving strategies, which is the criteria of selection. Using this model, three key variables were examined (1) student use of problem-solving strategies (2) which strategies were used and (3) the way in which the chosen strategy was expressed. These selection criteria were rigidly and consistently applied, the post-test was read through several times, in order to ensure the reliability and validity of the findings, and I sought help from my supervisor to do a second analysis to establish the validity and reliability of the coding.

The results will be presented in a descriptive manner.

\section{Basic statistics and comparison of results}

The second interpretation of the results is a quantitative study, namely a comparison study between two groups of students: those who were taught using the strategy thinking approach in the classroom and the control group containing two other classes. I analysed the three classes' conceptual and procedural knowledge in both the pre- and post-tests using mean, standard deviation and t-test for the experimental and control groups' test results. In order to look at the post-test and pre-test differences (PPD), I used the normalization z-score instead of the real score value, as the pre- and post-test results used different scales.

The absolute value of $\mathrm{z}$ represents the distance between the raw score and the population mean in units of the standard deviation. $\mathrm{z}$ is negative when the raw score is 
below the mean, positive when above. The z-score is a dimensionless quantity obtained by subtracting the population mean from an individual raw score and then dividing the difference by the population standard deviation.

$z_{i}=\frac{x_{i}-\mu}{\sigma}$

Where:

$\mu$ is the mean of the population

$\sigma$ is the standard deviation of the population.

\section{Results}

The results of this study will now be described in two different ways. I present quantitative results to describe how much is learned about the relevant mathematical concepts and procedures. I also present qualitative results to indicate to in what way the experimental groups have been affected in terms of their ability to use problem-solving strategies.

\subsection{Content analysis of post-test data}

The post-test data were analysed using content analysis, described earlier. Inductive content analysis is used because we don't have any previous studies dealing with the phenomenon of using strategies in problem-solving situations.

The solutions given by Student 1 show evidence of using strategies expressed both with words and through visual communication messages. In Task1 the student first puts circles around rational numbers in an arithmetical expression, in order to indicate that he is going to use the strategy Grouping of data. This way of highlighting grouping was frequently used by the teacher during the lessons on the strategy Organizing and grouping of data. The strategy is used in at least two different situations by this student, first in Task 1 when he notices that denominators and numerators can be cancelled pairwise in an arithmetic expression, and again in Task 2 when he uses the same strategy and visual communication to solve a task involving an algebraic expression, with the goal of finding out how many terms there are in an algebraic expression.

In Task 1 he continues by writing in words that he is trying to find a pattern and in Task 2 he explains with words that he is going to divide the data into those groups he found using the strategy Grouping data. He explicitly expresses his knowledge about different problemsolving strategies; hence he shows knowledge about more than one strategy that has been taught during the four weeks. He also shows that he knows that the same strategy can be used in different problem-solving situations.

We can see usage of the strategy Grouping data expressed through visual communication among the answers from other students. Student 2 puts circles around groups as a first step towards structuring the expression in Task 4 and after that works with these groups separately. In Task 3 the same student uses the strategy Grouping data to see 


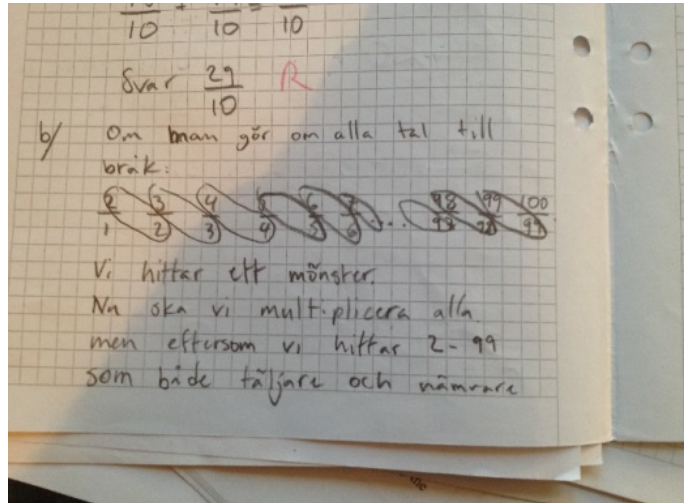

Figure 1 Task 1

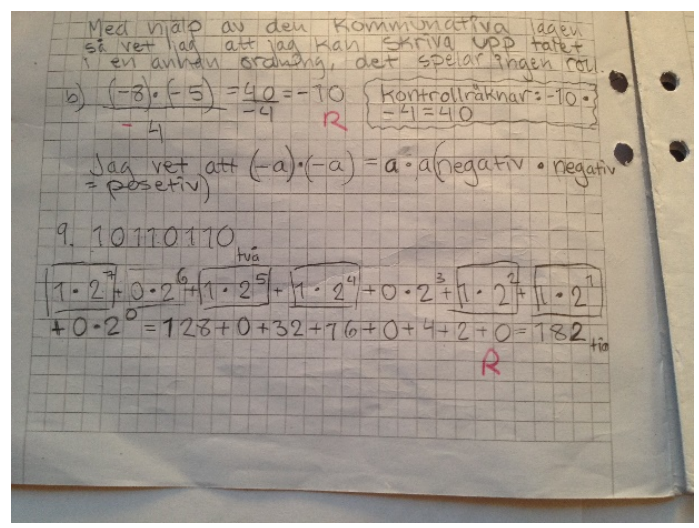

Figure 3 Task 3

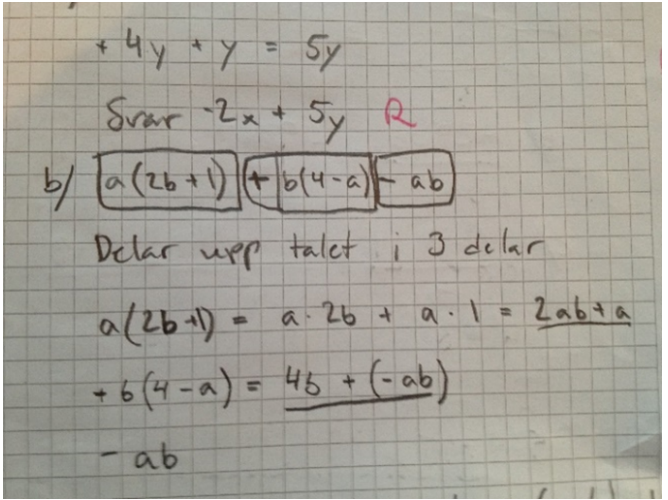

Figure 2 Task 2

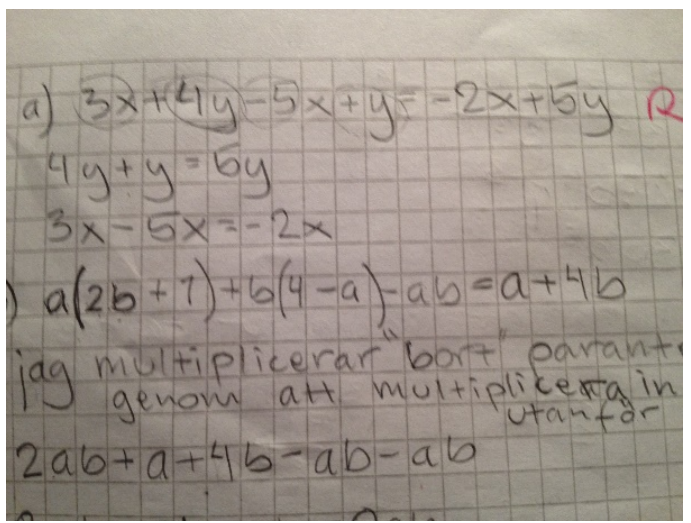

Figure 4 Task 4

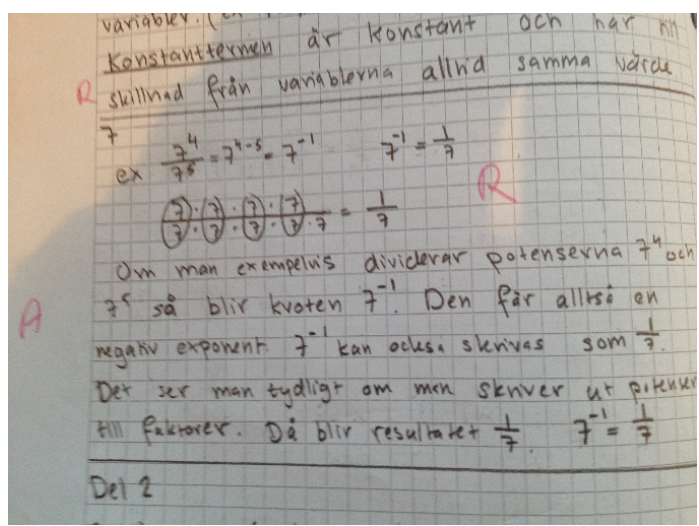

Figure 5 Task 5

which of the terms are not equal to zero. So in this case, in putting circles around some of the terms she is looking for a pattern at the same time (Find a pattern).

Another example of the use of the strategy Grouping data can found in the solution given by Student 3. She uses the circles as a visualization of the strategy Grouping data in the same way as the students discussed above. The task here is about properties of integer exponents. 
All these students are applying the strategy Organizing data with different goals in different tasks. Their goal may be to look for patterns, or to split the task into subtasks that are easier to solve.

Having corrected all the post-tests for both the experimental and the control groups, it became clear that students in the control group did not show any knowledge about problem-solving strategies and none of them gave any indication that they used any problem-solving strategies when constructing their answers to the post-test.

\subsection{Descriptive statistical analysis of procedural and conceptual development}

The main purpose of the second part of the results section is to do a comparison study to see whether the specially designed lesson with the aim of teaching strategies affects the students' conceptual and procedural knowledge. In the results of the post-test we can see the impact of the teaching intervention. We can't say if one or the other of the teaching methods is better for teaching procedural knowledge, but we can see that the experimental groups' procedural results are better than those of the other two classes. This is a good result as the experimental group had less time in the classroom to work with the tasks from the textbooks and practice tasks of a procedural nature, compared with the other two groups. The experimental group on the other hand spent more time in school discussing different ways to solve a task and learning about different problem-solving strategies than solving a lot of problems from the textbooks. This part of the learning was given as homework.

To assess the effect of the teaching intervention on the conceptual and procedural knowledge, we compared the differences between the post-test and pre-test results for each student for the three groups. The means and standard deviations are presented in Table 2. A positive value of the mean for the experimental group indicates that the group made good progress in these four weeks. If we compare with the control group, we see that the experimental group made better progress.

Table 2 Means and standard deviations of the experimental and control groups' test results and post-test/ pre-test differences (PPD)

\begin{tabular}{lrrrrrrrr}
\hline & \multicolumn{3}{c}{ Experimental group (N=26) } & & & \multicolumn{3}{c}{ Control group ( $\mathrm{N}=52)$} \\
\cline { 2 - 4 } \cline { 7 - 8 } & pre-test & post-test & PPD & & & pre-test & post-test & \multicolumn{1}{l}{ PPD } \\
\hline Mean & 0.0228 & 0.2449 & 0.222 & & & 0.0743 & -0.0683 & -0.143 \\
SD & 0.915 & 0.995 & 0.841 & & 0.972 & 1.0438 & 1.000 \\
\hline
\end{tabular}

The one sided t-test between the experimental and control groups in the post-test and pre-test differences (PPD) shows that there was a significant effect on the experimental groups.

$$
p=0.048 ; p<0.05 \text { one sided } t \text {-test }
$$

But analysis of covariance with pre-test results as a covariant (ANCOVA) doesn't show significant differences from the post-test (see Table 3). 
Table 3 Tests of Between-Subjects Effects ANCOVA with pre-test as a covariant

Dependent Variable: post

\begin{tabular}{lrrrrr}
\hline Source & Type III Sum of Squares & df & Mean Square & \multicolumn{1}{c}{ F } & Sig. \\
\hline Corrected Model & $22,093^{\mathrm{a}}$ & 2 & 11,046 & 15,262 & ,000 \\
Intercept &, 265 & 1 &, 265 &, 366 &, 547 \\
pre & 20,392 & 1 & 20,392 & 28,174 &, ,000 \\
group & 2,017 & 1 & 2,017 & 2,787 &, 099 \\
Error & 54,284 & 75 &, 724 & & \\
Total & 76,479 & 78 & & & \\
Corrected Total & 76,377 & 77 & & & \\
\hline
\end{tabular}

a. R Squared $=, 289$ (Adjusted R Squared $=, 270)$

\section{Discussion and conclusions}

In this paper, I study the effect of introducing teaching of mathematical problem-solving strategies into regular mathematics classroom teaching. I look at both the students' ability to use problem-solving strategies and at their development of conceptual and procedural knowledge.

First I discerned critical aspects of the concept of strategy by clarifying the differences and hierarchical relationship between the three concepts strategy, method and algorithm in a problem-solving situation.

Secondly I explored the educational possibilities of teaching problem-solving strategies. I discussed both theory and practice of teaching problem-solving strategies, the effects on the students' ability to use problem-solving strategies and on the students' conceptual and procedural knowledge.

\subsection{What is strategy?}

Two things suggested that the knowledge of methods and algorithms in mathematical problem-solving situations does not give the complete picture. First, by studying how strategies are used in many different areas, I realised that in problem solving in general one often speaks about three different stages with different goals and characteristics. Secondly from the teaching experiment it was obvious that if a student did not recognize how to solve the task, knowledge of methods and algorithms is not enough to solve the problem.

This suggests that the problem-solving process in mathematics should be seen as involving three qualitatively different stages, relating to knowledge about the strategy, method and algorithm, respectively. First a strategy must be selected - the thinking aspect of problem solving. I view a strategy as an approach that is not domain specific and is of general character, which focuses on the goal and the task as a whole, but which is flexible enough to allow for several ways to proceed when solving a problem. Strategies are abstractions that exist only in the minds of the interested parties, i.e. every strategy is an invention. Strategy is an overarching idea involving arranging or combining what is 
otherwise discrete and independent with a particular end in view. Secondly in the intersection between the thinking and the doing aspect there is a need for selecting a method that is a way of thinking to discover the relations of things, but at the same time specifying actions to solve the problem. In contrast with strategy, method should involve a progressive transition into the doing part. In this way, the method contributes regularity, repeatability and predictability. Method does not mechanize but devises a way to organize and clarify. Further, a method is not merely a means for reaching an envisaged end. Finally, an algorithm always leads to a result, describing step by step how to construct a possible solution to the original problem, a solution "that can be executed in the same way to solve a variety of problems arising from different situations and involving different numbers" (Kilpatrick et al., 2001).

\subsection{Educational opportunities to teach problem-solving strategies}

This paper summarizes the first four weeks of data of a year-long study. A significant part of the process of developing these lessons was to find appropriate tasks to teach the most common problem-solving strategies and the appropriate mathematical content. These tasks were meant to force learners to think in a particular way, to generate ideas on how to tackle the task by themselves, thereby helping them to approach mathematics from a different perspective. The teaching practices encouraged students to produce their own lists of strategies, to think about their own and other peoples' strategies and apply them accordingly to a variety of problems. At the same time learners had opportunities to experience a range of emotions associated with the problem-solving process.

The data from this study shows that it is possible to teach problem-solving strategies and strategy thinking within the limits of a mathematics classroom so that the students learn about strategies without losing out on conceptual or procedural knowledge. The posttest analysis showed that, of all the strategies mentioned in the lessons, students only use the strategies Grouping of data and Find a pattern. This result might have been expected, given how the post-test was constructed, partly because the opportunity for students to use other strategies was limited and partly because several of the tasks in the test might have led the students to focus on various standard procedures. Students who used the strategies showed an understanding of a critical aspect of strategy, namely that the same strategy can be used in different contexts or in the same context but in tasks with different character. The explicit use of strategies was rather modest in the experimental group after four weeks of teaching. However among the students in the control group there were no signs of any knowledge about problem-solving strategies and none of the students used strategies in their solutions. Hence I argue that it is of great importance to actively teach about problemsolving strategies if one wants students to develop the ability to use them in mathematical problem solving. The results in this paper demonstrate how the teaching of problemsolving strategies influences and changes the focus of students' learning. 
At the same time, by examining the lessons and the post-test, the study showed that learning about different strategies and realizing the benefits of using them is not a quick, easy, or step-by-step learning process.

Finally, the experimental group had better, or at least comparable, development in their conceptual and procedural knowledge compared with the control group: there were significant differences between the experimental and control groups in the post-test and pre-test differences (PPD).

As we noticed in Table 2, there is a difference between the means of the experimental and the control group in the procedural and conceptual development even after four weeks. But results of an ANCOVSA with pre-test results as a covariant don't show any significant differences. The difference might be a consequence of the fact that the students in the experimental group were able to develop a deeper understanding of some of the mathematical concepts. The opportunity to have more time in school to discuss different ways to solve a task might also have influenced their procedural knowledge. Since the lessons focused on activities that involved critical reflections and dialogues, the students had to work at home to practice the methods and algorithms that they had learned in class. In this way they probably spent more time on mathematics in general, which could also explain the result.

The result above shows that focusing on problem-solving strategies in upper secondary school will make a difference to students' mathematical knowledge. A reasonable conclusion is that it takes time to change the approach to teaching mathematics through focusing more on teaching problem-solving strategies, but this can give students a powerful tool in problem-solving situations.

Since the national test in mathematics measures, among other things, the students' problem-solving ability at the end of every mathematics course, the data from the analysis of the national tests could also be used in the future to investigate the effects of the specially designed lessons on the students' problem-solving ability.

\subsection{Limitations}

Since one person was acting as a designer, teacher and researcher, some ethical questions could be raised. To avoid the teacher-researcher conflict in the classroom (for example having to choose between helping a student and holding back as a researcher to see what will happen), I made a decision. The teaching agenda was my main focus during class time and when I was outside the classroom I would reflect on and scrutinize my teaching with the research goals in mind. The fact that the designer and the teacher are the same person can be an advantage in, for example, detecting what the students find difficult and in the improvement of the lesson design for the next cycle. An important lesson was to begin to see the problems through the eyes of the students who were solving it. What the student sees is not always the same as what the designer sees. 
Focusing on a single case has its limitations but also its benefits. It became possible to explore motivations, interactions and conflicts in a deeper way. The case study is particularly appropriate to exploratory research, providing evidence that integrating teaching, research and design work is possible, and exploring the complexities of bringing these communities together.

\section{References}

Akker, J., van den (1999). Principles and methods of development research. In J. van den Akker, R. Branch, K. Gustafson, N. Nieveen, \& Tj. Plomp (Eds.), Design and development methodology in education (pp. 1-14). Dordrecht: Kluwer.

Anderson, T. \& Shattuck, J (2011). Design-based research: a decade of progress in education research? Education Researcher, 41(1), 16-25.

Anderson T. (2005). Design-based research and its application to a call center innovation in distance education. Canadian Journal of Learning and Technology, 31(2), 69-84.

Ansoff, H. I. (1991). Critique of Henry Mintzberg's 'The Design School: Reconsidering the Basic Premises of Strategic Management. Strategic Management Journal, 12, 449-461.

Armstrong, J. S (1982). The value of formal planning for strategic decisions: Review of empirical research. Strategic Management Journal, 3, 197-211

Brown, A.L. (1992). Design experiments: Theoretical and methodological challenges in creating complex interventions in classroom settings. The Journal of the Learning Sciences, 2(2), 141-178.

Cai, J. (2003). What research tells us about teaching mathematics through problem solving. In F. K. Lester, Jr. (Ed.), Research and issues in teaching mathematics through problem solving (pp. 241254). Reston, VA: National Council of Teachers of Mathematics.

Casey, A. \& Goldman, E. (2010). Enhancing the ability to think strategically: A learning model. Journal of Management Learning, 41, 167-185.

Carpenter, T. P., Franke, M. L., Jacobs, V. R., Fennema, E., \& Empson, S. B. (1998). A longitudinal study of invention and understanding in children's multidigit addition and subtraction. Journal for Research in Mathematics Education, 29, 3-20.

Cobb, P., Confrey, J., diSessa, A., Lehrer, R., \& Schauble, L. (2003) Design experiments in educational research. Education Researcher, 32(1), 9-13.

Cobb, P. (Ed.). (1994). Learning mathematics: Constructivist and interactionist theories of mathematical development. Dordrecht: Kluwer.

Cole F.L. (1988) Content analysis: process and application. Clinical Nurse Specialist 2(1), 53-57.

Collins, A. (1992). Toward a Design Science of Education. In E. Scanlon \& T. O'Shea (Eds.), New directions in educational technology (pp. 15-22). New York: Springer.

Collins, A. (1999). "The changing infrastructure of education research" In E. C. Lagemann \& L. S. Shulman (Eds.), Issues in Education Research: Problems and possibilities. San Francisco, CA: Jossey-Bass.

Design-Based Research Collective (2003). Design-based research: An emerging paradigm for educational inquiry. Educational Researcher, 32(1), 5-8.

Edelson, D.C. (2002). Design research: What we learn when we engage in design. The Journal of the learning sciences, 11(1), 105-121.

Grant, R. M. (2008). Contemporary strategy analysis. Oxford: John Wiley and Sons.

Gravemeijer, K. \& Doorman, M. (1999). Context Problems in Realistic Mathematics Education: A Calculus Course as an Example. Educational Studies in Mathematics, 39(1-3), 111-129. 
Grinyer, P., Al-Bazzaz, S., \& Yasai-Ardekani, M. (1986). Towards a contingency theory of corporate planning: Findings in 48 U.K. companies. Strategic Management Journal, 7, 3-28.

Goldman, E. (2012). Leadership practices that encourage strategic thinking. Journal of Strategy an management, 5(1), 25-40.

Hatano, G. (1988). Social and motivational bases for mathematical understanding. In G. B. Saxe \& M. Gearhart (Eds.), Children's mathematics: New directions for child development (pp. 55-70). San Francisco, CA: Jossey-Bass.

Hiebert, J., Carpenter, T. P, Fennema, E., Fuson, K. C., Wearne, D., \& Murray, H. (1997). Making sense: Teaching and learning mathematics with understanding. Portsmouth, NH: Heinemann.

Hiebert, J. \& Wearne, D. (1993). Instructional task, classroom discourse, and students' learning in second grade. American Educational Research Journal, 30, 393-425.

Häggström, J. (2008). Teaching systems of linear equations in Sweden and China: what is made possible to learn? Gothenburg: Göteborgs universitet.

Kilpatrick, J., Swafford, J., \& Findell, B. (2001). Adding it up: Helping children learn mathematics. Washington, D.C.: National Academy Press.

Krippendorff, K. (1980). Content Analysis: An Introduction to its Methodology. Beverly Hills, CA: Sage.

Kullberg, A. (2010). What is taught and what is learned. Professional insight gained and shared by teachers of mathematics. In series Göteborg studies in educational sciences 293. Acta Universitatis Gothoburgensis. Gothenburg: Göteborgs universitet.

Lester, F., \& Kroll, D. (1993). Assessing student growth in mathematical problem solving. In G. Kulm (Ed.), Assessing higher order thinking in mathematics (pp.53-70), Washington, DC: American Association for the Advancement of Science.

Magidson, S. (2005). Building bridges within mathematics education: Teaching, research, and instructional design. Journal of Mathematical Behavior, 24, 135-169.

Mason, J. Burton, L., \& Stacey, K. (1982). Thinking mathematically. London: Pearson.

Marton, F. \& Booth, S. (2000). Om lärande. Lund: Studentlitteratur

Marton, F. \& Tsui, A. (2004) Classroom discourse and the space of learning. Mahwah: Lawrence Erlbaum

Mintzberg, H. (1994). The fall and rise of strategic planning. Harvard Business Review, JanuaryFebruary, 107-114.

National Council of Supervisors of Mathematics, NCSM (1977). Position paper on basic mathematical skills. Golden, CO: Author.

Pang, M.F. \& Marton, F. (2005) Learning theory as teaching resource: Enhancing students' understanding of economic concepts. Instructional Science, 33(2), 159-191.

Pólya, G. (1945). How to solve it. Princeton, NJ: Princeton University Press.

Pólya, G. (1962). Mathematical discovery, on understanding, learning and teaching problem solving. New York, NY: John Wiley \& Sons.

Posamentier, A.S. \& Krulik, S.(1998) Problem-solving strategies for efficient and elegant solutions, Thousand Oaks, CA: Corwin Press.

Richey, R. C., Klein, J.D., \& Nelson, W. (2003). Developmental research: Studies of instructional design and development. In D. Jonassen (Ed.), Handbook of research for educational communications and technology (pp. 1099-1130). Mahwah, NJ: Lawrence Erlbaum Associates.

Reigeluth, C. M. \& Frick, T. W. (1999). Formative research: a methodology for improving design theories. In C. M. Reigeluth (Ed.), Instructional-design theories and models: a new paradigm of instructional theory (pp. 633-651). Mahwah, NJ: Lawrence Erlbaum Associates.

Runesson, U. (2008). Learning to design for learning. The potential of learning study to enhance learning on two levels: Teachers' and students' learning. In T. Wood \& P. Sullivan (Eds.), Knowledge and beliefs in mathematics teaching and teaching development. Rotterdam: Sense Publishers. 
Serván, M. J.; Soto, E. et al (2009). Problem-based learning and action research in post-graduate teaching: The interdisciplinary core. Educational Action Research, 17(3), 373-389.

Sloan, J. (2006). Learning to Think Strategically. Oxford: Taylor \& Francis

Schoenfeld, A. H. (Ed.) (1983). Problem solving in the mathematics curriculum: A report, recommendations, and an annotated bibliography. Washington, DC: Mathematical Association of America.

Schoenfeld, A.H. (1985). Mathematical Problem Solving. Orlando, FL: Academic Press.

Stigler, J. W. \& Hiebert, J. (1999). The teaching gap. New York, NY: Free Press.

Swedish National Agency for Education (2011) http://www.skolverket.se/laroplaner-amnen-ochkurser/gymnasieutbildning/gymnasieskola/sok-amnen-kurser-och-program

Zhang,J., Scaramalia,M., Reeve,R., \& Messina,R. (2009). Designs for collective cognitive responsibility in knowledge - building communities. The Journal of the learning sciences, 18, 744.

Zagare, F. (1984) Game theory: Concepts and applications. Beverly Hills, CA: Sage.

Vego, M. (2012). Thinking Between Strategy \& Tactics. In United States Naval Institute Proceedings (Vol. 138, No. 2, p. 62).

Wang, F., \& Hannafin, M. J. (2005). Design-based research and technology-enhanced learning environments. Educational technology research and development, 53(4), 5-23.

Wernberg, A. (2009). Lärandets objekt: vad elever förväntas lära sig, vad görs möjligt för dem att lära och vad de faktiskt lär sig under lektionerna. Umeå \& Kristianstad: Umeå universitet \&Högskolan Kristianstad. 